\title{
FORMULATION AND EVALUATION OF MICONAZOLE NITRATE NANOEMULSION AND CREAM
}

\author{
HETTY LENDORA MAHA ${ }^{1 *}$, KASMIRUL RAMLAN SINAGA ${ }^{1}$, MASFRIA ${ }^{2}$
}

${ }^{1}$ Department of Pharmaceutics, Faculty of Pharmacy, University of Sumatera Utara, Medan, Indonesia. ${ }^{2}$ Department of Biological Pharmacy, Faculty of Pharmacy, University of Sumatera Utara, Medan, Indonesia. Email: hetty_maha03@yahoo.co.id

Received: 16 August 2017, Revised and Accepted: 11 December 2017

ABSTRACT

Objective: The present study is to determine the evaluation profile of the preparations nanoemulsion and cream of miconazole nitrate.

Methods: Preparation of nanoemulsi with concentrations 1\%, 1.5\%, and 2\% using the principle of low-energy emulsification and miconazole nitrate cream was then performed physical evaluation of the preparation which included organoleptic test, pH measurement, viscosity test, emulsion type, cycling test, centrifugation test, particle size measurement with particle size analyzer, and homogeneity test of cream preparations.

Result: Based on organoleptic test, it can be seen that the miconazole nitrate nanoemulsion preparations produced are clear, colored weak yellow, and the cream is white. The average $\mathrm{pH}$ of the nanoemulsion preparations ranged from 6.01 to 6.25 , while the cream preparations were 5.95-6.52. The average viscosity values of nanoemulsion preparations were $1707 \mathrm{cps}, 1920 \mathrm{cps}$, and $1987 \mathrm{cps}$, respectively. In the cycling test, the nanoemulsion preparation remained weak yellow and odorless, and the cream preparation remained white and did not experience phase separation. In the centrifugation test, the nanoemulsion preparation and the cream were centrifuged at a rate of 3800 for 5 h, after centrifugation tests, both the nanoemulsing and cream preparations did not show any phase separation, in the nanoemulsion preparation possibly due to the high viscosity of the preparation. On the type nanoemulsi test, by dripping methylene blue on the formula. After observed, the blue methylene is evenly dispersed into the formula, indicating that all four formulas have an oil-in-water emulsion type (o/w). The particle size of the nanoemulsion preparation ranged from $102.36 \mathrm{~nm}$ to $309.11 \mathrm{~nm}$

Conclusion: The results of evaluation of miconazole nitrate nanoemulsion preparations were better than cream preparations.

Keywords: Nanoemulsion, Cream, Miconazole nitrate, Antifungal, Topical preparation.

(C) 2018 The Authors. Published by Innovare Academic Sciences Pvt Ltd. This is an open access article under the CC BY license (http://creativecommons. org/licenses/by/4. 0/) DOI: http://dx.doi.org/10.22159/ajpcr.2018.v11i3.22056

\section{INTRODUCTION}

Miconazole nitrate is one of the broad spectrum antifungal compounds of the imidazole group [1]. This antifungal agent is a fungicide used in the treatment of fungal infections in a topical and transdermal [2]. This drug works by inhibiting ergosterol biosynthesis on the fungal cell membranes that cause damage to the cell wall of the fungus, resulting in increased membrane permeability, and ultimately, causing the fungal cell to lose its cellular nutrients. The drug is mainly used for the treatment of mycosis skin diseases [3]. The bioavailability of miconazole nitrate is very low when taken orally because it is very difficult to dissolve and has a small absorption, and therefore, the use of miconazole nitrate as an antifungal agent is given topically, but the main problem of this drug in topical treatment is poor skin penetration [4].

To design effective formulations of miconazole nitrate has long been a major challenge due to the very limited efficacy due to the unstable or poor drug solubility in the carrier. One of the pharmaceutical preparations that can be used in a drug delivery system to overcome the above problem is a nanoemulsion drug delivery system, which is applied to improve solubility and bioavailability of a lipophilic drug [5].

Nanoemulsi does not creaming, sedimentation, and flocculation or coalescence compared to macroemulsions [14]. Nanoemulsi also has the potential as a carrier in topical treatment because it is able to optimize the dispersion of active substances in the skin layer [2]. Based on the above background, the researchers conducted research on the development of formulations of miconazole nitrate in the form of nanoemulsion with better hope and effective as an antifungal.

\section{METHODS}

Preparation of miconazole nitrate nanoemulsion

The ingredients of the oil phase, namely, oleic acid are added with miconazole nitrate stirred with magnetic stirrers to homogeneous. Meanwhile, the aqueous phase including sodium metabisulfite and aqua bidestilate was mixed and stirred with a stirring bar until homogeneous.

In a separate container, an emulgator comprising Tween 80 and PEG 400 is mixed and stirred with a magnetic stirrer up to homogeneous. Next, the oil phase is added to the water phase while the addition of the emulsifier mixture is piecemeal and stirred using a magnetic stirrer. After all the ingredients are mixed, then the mixture of the material homogenized using a homogenizer which is set at $1000 \mathrm{rpm}$ for $60 \mathrm{~min}$, after it was sonificated using sonicator for $30 \mathrm{~min}$ until it was formed the clear nanoemulsion [6].

\section{Measurement of nanoemulsion particle size distribution}

The particle size was measured using a particle size analyzer (PSA). Drops of 4 drops of the formulation miconazole nitrate nanoemulsion at the site of the sample in the PSA. Then, the instrument closes and reads the measurement results on a computermonitor directly connected to the PSA.

Organoleptic test of miconazole nitrate nanoemulsion

The organoleptic test of the nanoemulsion preparation was performed visually including color, odor, phase separation or nanoemulsion rupture, and clarity [7].

\section{pH measurement}

Measurement of $\mathrm{pH}$ of the formula was done using $\mathrm{pH}$-meter. First, the electrode is calibrated in advance with a neutral buffer standard 
( $\mathrm{pH} 7.01)$ and a buffer solution of acidic $\mathrm{pH}(\mathrm{pH} 4.01)$. Then, the electrode is immersed in a nanoemulsion preparation. The $\mathrm{pH}$ value listed on the tool is recorded. Measurements were made at room temperature [8].

\section{Measurement of viscosity}

The viscosity of the formula was measured using a Brookfield viscometer at room temperature $\left(28^{\circ} \mathrm{C} \pm 20^{\circ} \mathrm{C}\right)$. The formula was inserted into a beaker glass until it becomes a $100 \mathrm{ml}$ formula, then the spindle is lowered until the spindle boundary was immersed in the preparation. Spindle used is spindle number 3 . Then, the viscometer was turned on by pressing the on button. Then, the spindle speed is set at the used rpm (30 rpm). Then, read the scale (dial reading) where the moving red needle has stabilized. The viscosity value in centipoise (cps) is obtained from the multiplication of dial reading with correction factor.

\section{Test of the nanoemulsion type}

The test of nanoemulsion type was performed by sprinkling a water soluble, namely, methylene blue, on the surface of the nanoemulsion on top of the cleaned object glass. If nanoemulsion is a type of oil in water, then the methylene blue will dissolve in it and diffuse evenly throughout the water. If nanoemulsion is a type of water in oil, the methylene blue particles will cluster on its surface [9].

\section{Cycling test}

The nanoemulsion preparation is stored at $4^{\circ} \mathrm{C} \pm 2^{\circ} \mathrm{C}$ for $24 \mathrm{~h}$, then into the oven at $40^{\circ} \mathrm{C} \pm 2^{\circ} \mathrm{C}$ for the next $24 \mathrm{~h}$. This treatment is one cycle. The experiment was repeated for 6 cycles. After a cycling test, see the physical condition of nanoemulsion before and after the test [7].

\section{Centrifugation test}

The sample is inserted into a centrifugation tube then inserted into a centrifugator with a spin speed $3800 \mathrm{rpm}$ for $5 \mathrm{~h}$. Treatment results are equivalent to a gravity effect for 1 year. After centrifugation was observed, the physical condition of the preparation compared before and after the test [8].

\section{Formulation miconazole nitrate cream}

\section{Preparation of miconazole nitrate cream}

All necessary materials are weighed. The materials are separated into two groups: The oil phase and the water phase. The oil phase consists of vaseline, stearic acid, and cetyl alcohol melted over a water bath with a temperature of $70-75^{\circ} \mathrm{C}$. After a perfect melt was added, miconazole nitrate into it. In a separate container, aqueous phases comprising aquadest, propylene glycol, and TEA are dissolved in hot water. On a continuous phase, the water in a hot melt is then slowly added to the oil phase with a constant stirring at a temperature more or less $70^{\circ} \mathrm{C}$, until a cream mass was obtained [10].

\section{Homogeneity test of the miconazole nitrate cream}

As many as $50 \mathrm{mg}$ of cream preparations smeared on a clean object glass, the preparation should show a homogeneous arrangement and no visible grain [10].

\section{Physical evaluation of miconazole nitrate}

Physical evaluation of the cream preparations of miconazole nitrate includes organoleptic testing, $\mathrm{pH}$, and type of emulsion.

\section{RESULTS AND DISCUSSION}

\section{Homogenitas sediaan krim}

The aim of homogeneity test was to show the materials distribution in the formula. Based on the homogeneity, observation of cream formula had been shown not any coarse grains found on object glass so that should be concluded that this formula was homogeneous as presented in Fig. 1.

\section{Organoleptic observation}

All nanoemulsion formulations were made clear, odorless, and weak yellow color, while the cream preparation is white, odorless, and no phase separation occurs. All formulas have no significant difference during storage.

\section{pH measurement}

The $\mathrm{pH}$ of a topical preparation should be within the $\mathrm{pH}$ range corresponding to the $\mathrm{pH}$ of the skin, namely, 4.5-6.5. The pH should not be too acidic as it may cause skin irritation and should not be too alkaline

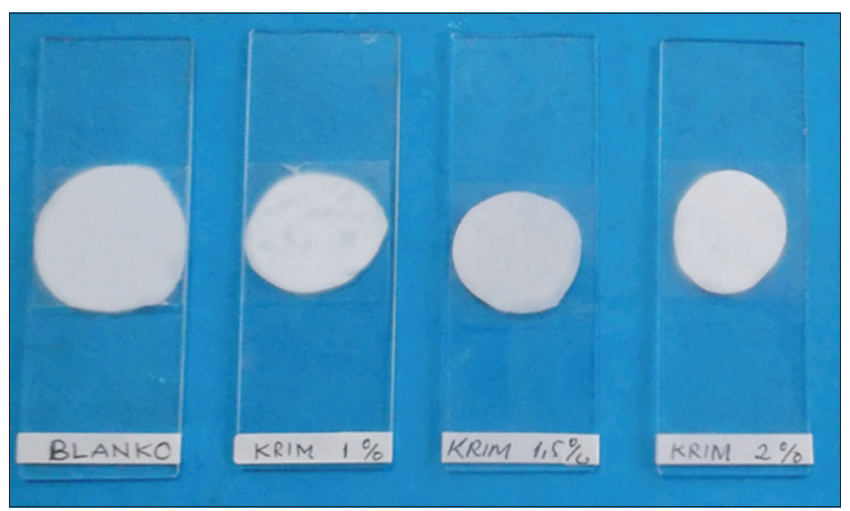

Fig. 1: Homogeneity of prepared cream

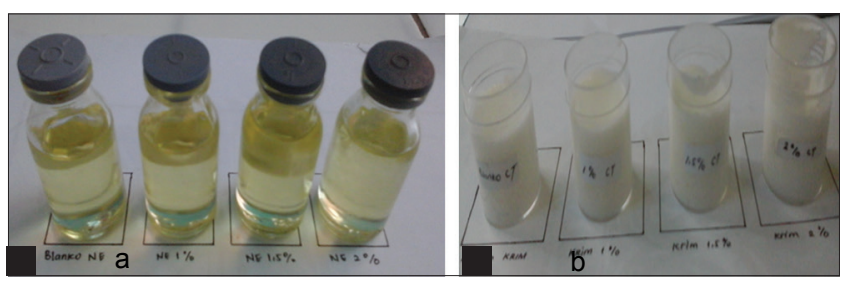

Fig. 2: (a and b) Formula after cycling test

Table 1: Miconazole nitrate nanoemulsion formula

\begin{tabular}{lllll}
\hline Ingredients & F1 & F2 & F3 & F4 \\
\hline Miconazole nitrate (\%) & - & 1 & 1.5 & 2 \\
Oleic acid (\%) & 8 & 8 & 8 & 8 \\
Tween 80 (\%) & 25 & 25 & 25 & 25 \\
PEG 400 (\%) & 5 & 5 & 5 & 5 \\
Sodium metabisulfite (\%) & 0.1 & 0.1 & 0.1 & 0.1 \\
Aqua bidest ad (ml) & 100 & 100 & 100 & 100 \\
\hline
\end{tabular}

Table 2: Formulation miconazole nitrate cream

\begin{tabular}{lllll}
\hline Ingredients & F1 & F2 & F3 & F4 \\
\hline Miconazole nitrate (\%) & - & 1 & 1.5 & 2 \\
Vaseline (\%) & 5 & 5 & 5 & 5 \\
Cetyl alcohol (\%) & 3 & 3 & 3 & 3 \\
Stearic acid (\%) & 3 & 3 & 3 & 3 \\
Glyceryl monostearate (\%) & 3 & 3 & 3 & 3 \\
Propylene glycol (\%) & 5 & 5 & 5 & 5 \\
TEA (\%) & 1 & 1 & 1 & 1 \\
Sodium metabisulfite (\%) & 0.1 & 0.1 & 0.1 & 0.1 \\
Aqua bidest ad (g) & 100 & 100 & 100 & 100 \\
\hline
\end{tabular}

Table 3: The result of $\mathrm{pH}$ measurement at 0 week and $8^{\text {th }}$ week

\begin{tabular}{llllll}
\hline \multirow{2}{*}{ Formulation } & \multicolumn{2}{l}{ Nanoemulsion } & & \multicolumn{2}{l}{ Cream } \\
\cline { 2 - 3 } \cline { 6 - 6 } \cline { 5 - 6 } & $\mathbf{0}$ week & $\mathbf{8}^{\text {th }}$ week & & 0 week & $\mathbf{8}^{\text {th }}$ week \\
\hline Blanko & 6.24 & 6.25 & & 6.50 & 6.51 \\
F1 & 6.13 & 6.14 & & 5.95 & 6.00 \\
F2 & 6.07 & 6.09 & & 5.94 & 5.95 \\
F4 & 6.01 & 6.04 & & 5.91 & 5.93 \\
\hline
\end{tabular}



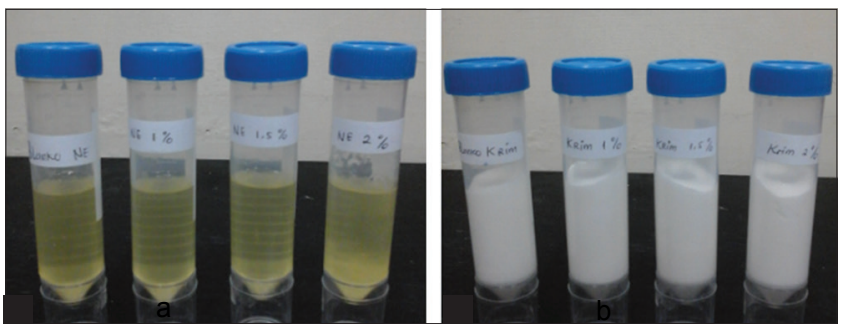

Fig. 3: ( $a$ and $b$ ) The formula after centrifugation test

Table 4: The result of viscosity measurement at 0 week and $8^{\text {th }}$ week

\begin{tabular}{lll}
\hline Formulation & \multicolumn{2}{l}{ Average viscosity (cps) } \\
\cline { 2 - 3 } & 0 week & $\mathbf{8}^{\text {th }}$ week \\
\hline Blanko & 1000 & 1600 \\
F1 & 1013 & 1707 \\
F2 & 1107 & 1920 \\
F3 & 1160 & 1987 \\
\hline
\end{tabular}

Table 5: The particle size of miconazole nitrate nanoemulsion at the time before and after 8 weeks storage at room temperature

\begin{tabular}{llllll}
\hline Formula & \multicolumn{2}{l}{ Before storage } & & \multicolumn{2}{l}{ After storage } \\
\cline { 2 - 3 } \cline { 5 - 6 } & $\begin{array}{l}\text { Particle } \\
\text { size }\end{array}$ & Intensity & & $\begin{array}{l}\text { Particle } \\
\text { size }\end{array}$ & Intensity \\
& $102.36 \mathrm{~nm}$ & 0.51 & & $177.88 \mathrm{~nm}$ & 0.59 \\
\hline $\mathrm{F} 2$ & $112.23 \mathrm{~nm}$ & 0.47 & & $234.49 \mathrm{~nm}$ & 0.47 \\
$\mathrm{~F} 3$ & $117.52 \mathrm{~nm}$ & 0.71 & & $309.11 \mathrm{~nm}$ & 0.52 \\
\hline $\mathrm{F} 4$ & & & & &
\end{tabular}

as it may cause scaly skin [11]. Based on pH measurements for 8 weeks, all nanoemulsion and cream formulations of miconazole nitrate were changed. However, the change in $\mathrm{pH}$ has not changed significantly and was still within the $\mathrm{pH}$ range of the skin. The $\mathrm{pH}$ measurement results can be seen in Table 3.

\section{Measurement of viscosity}

Based on the result of viscosity, obtained an increase in viscosity value so it can be said that nanoemulsion has stability after 8 weeks of at room temperature. The increase in the viscosity of the four nanoemulsion formulations is possible due to the reasonably low room temperature. Viscosity is inversely proportional [9]. Decrease in viscosity during storage will indicate that kinetic unstable emulsions where free moving droplets will collide with each other and tend to coalesce [8]. Viscosity values obtained from the multiplication of the dial reading and correction factors that exist in the Brookfield viscometer. The result of viscosity test can be seen in Table 4 .

\section{Cycling test}

All the formulas on the cycling test after 6 cycles, the nanoemulsion preparation remained weak yellow and odorless, and the cream preparations remained white and did not show phase separation.

\section{Centrifugation test}

After all the formula was centrifuged at $3800 \mathrm{rpm}$ for $5 \mathrm{~h}$, both nanoemulsion and cream preparations did not show phase separation.

\section{Observation of emulsion type}

Based on the nanoemulsi type observation, by dripping methylene blue on the formula. Once observed, the blue methylene is evenly dispersed into the formula, indicating that all four formulas have an oil in water emulsion type $(\mathrm{m} / \mathrm{a})$

\section{Nanoemulsion particle size measurements}

Based on particle size measurements using PSA, nanoemulsion preparations containing $1 \%$ miconazole nitrate had the smallest particle size before and after storage, namely, $\quad 102.36 \mathrm{~nm}$ and $177.88 \mathrm{~nm}$. The higher concentration of miconazole nitrate in the preparation results in greater nanoemulsion. From the results, it appears that particles more than $100 \mathrm{~nm}$ in size before and after storage, but the particle size is still in the provisions of the specified nanoemulsion dosage size in the range of $2-500 \mathrm{~nm}$ [12]. This theory is also supported by research by Shahid and Chowdeswari which states that nanoemulsion can be defined as an oil in water emulsion having a droplet diameter of $50-1000 \mathrm{~nm}$. Usually, the average droplet size is between 100 and $500 \mathrm{~nm}$ [13]. The particle size measurement results can be seen in Table 5 .

CONCLUSION

The results of evaluation nanoemulsion were better than cream preparations.

\section{ACKNOWLEDGMENTS}

The author would like to thank the Faculty of Pharmacy and Dean for the support and providing the research work.

\section{AUTHOR CONTRIBUTION}

Hetty Lendora Maha was contributed.

\section{CONFLICT OF INTEREST}

Conflict of interest declared none.

\section{REFERENCES}

1. Sanap GS, dan Mohanta P. Development of miconazole nitrate controlled release formulations based on SLN and NLC for topical delivery. Int J Pharm Pharm Sci 2014;6:393-9.

2. Samira S, Ali MT, Fakhr S, Saed D, dan Hamidrwza M. Pharmaceutical nanoemulsion and their potential topical and transdermal applications. Iran J Pharm Sci 2015;7:139-50.

3. Gossel TA. Topical antifungal products. U.S Pharm J 1985;10:44-6.

4. Tenjarla S, Puranajoti P, Kasina R, Mandal T. Preparation, characterization, and evaluation of miconazole-cyclodextrin complexes for improved oral and topical delivery. J Pharm Sci 1998;87:425-9.

5. Shinde PB. Component screening of miconazole nitrat nanoemulsion. Asian J Biomed Pharm Sci 2013;3:33-40.

6. Vijaya RS, Suresh K, dan Kamalakannan S. Preparation and in vitro evaluation of miconazole nitrat nanoemulsion using tween 20 as surfactant for effective topical/transdermal delivery. J Chem Pharm Sci 2015;1:92-8.

7. Suciati T, Aliyandi A, dan Satrialdi. Development of transdermal nanoemulsion formulation for simultaneous delivery of protein vaccine and Artin-M adjuvant. Int J Pharm Pharm Sci 2014;6:536-41.

8. Sambasivarao A, Rao CS, dan Reddy HM. Accelerated stability testing of dosages forms as per international conference of hormozination (ICH) guidelines. World J Pharm Med Res 2016;2:99-103.

9. Abdulkarim MF, Abdullah GZ, Chitneni M, Mahdi ES, Yam MF, Faisal A, et al. Stability studies of nano-cream containing piroxicam. Int J Drug Deliv 2010;2:333-9.

10. Martin A, Swarbrick J, dan Cammarata A. Farmasi Fisik. Edisi Ketiga. Diterjemahkan oleh Joshita Djajasastra. Jakarta: Universitas Indonesia Press; 1993. p. 1014-145.

11. Syamsuni HA. Ilmu Resep. Jakarta: EGC Penerbit buku kedokteran; 2006. p. 74-5.

12. Wasitaatmadja SM. Penuntun Ilmu Kosmetik Medik. Jakarta: Penerbit Universitas Indonesia; 1997. p. 62-3, 111-2.

13. Tadros TF. Applied Surfactans: Principle and Application. Weinheim: Wiley-VCH Verlag $\mathrm{GmbH}$ and Co; 2005. p. 115-7.

14. Shahid MS, dan Chowdeswari A. A review on nanoemulsion. Scand J Pharm Sci Res 2013;1:6-9.

15. Guglielmini G. Nanostructured novel carrier for topical application. Clin Dermatol 2008;26:341-6. 